\title{
Riscos de corrupção e infrações conexas: o caso dos institutos politécnicos públicos portugueses
}

\author{
Corruption risks and connected infractions: the case of portuguese public polytechnic \\ institutes
}

Riesgos de corrupción e infracciones conectadas: el caso de los institutos politécnicos públicos portugueses

\section{Carla Isabel Dias Cabrita Cardoso}

Mestre em Contabilidade e Finanças pela Escola Superior de Ciências Empresariais do Instituto Politécnico de Setúbal

Técnica de Contabilidade na Empresa Sacramento Campos-Projetos e Serviços, S.A.

Endereço: Parque Proclama - Quinta da Areia - Coina

CEP: 2830-481, Barreiro - Portugal

E-mail: carly.cardoso@hotmail.com

Telefone: 351966814939

\section{Sandra Cristina Dias Nunes}

Doutora em Matemática pela Faculdade de Ciências e Tecnologia da Universidade Nova de Lisboa

Professora do Mestrado em Contabilidade e Finanças da Escola Superior de Ciências

Empresariais do Instituto Politécnico de Setúbal

Endereço: Campus do IPS. Estefanilha

CEP: 2914 - 503, Setúbal - Portugal

E-mail: $\underline{\text { sandra.nunes@esce.ips.pt }}$

Telefone: 351265709300

\section{Maria Teresa Venâncio Dores Alves}

Doutora em Gestão pelo Instituto Superior de Ciências do Trabalho e das Empresas

Professora do Mestrado em Contabilidade e Finanças da Escola Superior de Ciências

Empresariais do Instituto Politécnico de Setúbal

Endereço: Campus do IPS. Estefanilha

CEP: 2914 - 503, Setúbal - Portugal

E-mail: teresa.alves@esce.ips.pt

Telefone: 351265709300

Artigo recebido em 25/06/2014. Revisado por pares em 15/10/2014. Reformulado em 10/11/2014. Recomendado para publicação em 15/11/2014 por Sandra Rolim Ensslin (Editora Científica). Publicado em 15/12/2014. 


\title{
Resumo
}

No setor público, tal como em qualquer outro setor, a gestão do risco é uma necessidade. Trata-se de uma atividade cujo exercício contribui para a melhoria da prestação do serviço público. $\mathrm{O}$ ensino superior politécnico é reconhecido como um dos setores pilares do serviço público. $\mathrm{O}$ presente estudo tem como objetivo verificar o nível de divulgação de informação sobre o risco apresentado pelos Institutos Politécnicos (IP's) portugueses. Para o efeito adotou-se o método qualitativo e o método quantitativo. Através de testes estatísticos, procurou-se eventuais relações entre o número de riscos/processos e o número de escolas e de cursos; população e massa monetária. Verificou-se a existência de diferentes níveis de divulgação de informação sobre o risco entre os IP's públicos portugueses e constatou-se a inexistência de uma relação estatisticamente significativa entre o número de riscos e a dimensão do Instituto.

Palavras-chave: Riscos de corrupção. Divulgação. Setor público. PGRCIC.

\begin{abstract}
In the public sector, as in any other sector, risk management became a necessity. It is an activity whose exercise contributes to a better performance of public service delivery. Higher polytechnic education is recognized as one of the pillars of the public service. The present study main objective is to check the level of information risk disclosure showed by the Portuguese public Polytechnic Institutes. In order to achieve that, we have followed both the qualitative and the quantitative methods of research. Through various statistical tests, the study tries to find possible relationships between the number of risks / processes and the number of schools and courses, population and money supply. The results show the existence of different levels of information risk disclosure among the Portuguese public Polytechnic Institutes, and no statistically significant relationship between the number of risks and the size of the Institute.
\end{abstract}

Keywords: Corruption risks. Disclosure. Public sector. PGRCIC.

\section{Resumen}

En el sector público, como en cualquier otro sector, la gestión de riesgos se convirtió en una necesidad. Es una actividad cuyo ejercicio contribuye a la mejor actuación de prestación de servicios públicos. La Educación Superior Politécnica es reconocida como uno de los pilares de la administración pública. El objetivo principal del presente estudio es comprobar el nivel de divulgación de información sobre riesgos demostrado por los institutos politécnicos públicos portugueses. Para ello, hemos seguido el método cualitativo y el método cuantitativo de investigación. Través de diversas pruebas estadísticas, el estudio trata de encontrar posibles relaciones entre el número de riesgos / procesos y el número de escuelas y cursos, población y masa monetaria. Los resultados muestran la existencia de diferentes niveles de divulgación de información sobre riesgos entre los institutos politécnicos públicos portugueses y ninguna relación estadísticamente significativa entre el número de riesgos y el tamaño del Instituto.

Palabras clave: Riesgos de corrupción, divulgación, sector público, PGRCIC. 


\section{Introdução}

Qualquer organização enfrenta riscos independentemente do seu tipo ou dimensão. O risco é, com frequência, caracterizado como a possibilidade de um determinado acontecimento poder ocorrer e gerar um resultado diferente do esperado. O impacto desse acontecimento nos resultados de cada atividade determina o grau de risco da organização.

O Conselho de Prevenção da Corrupção (CPC), um organismo independente que funciona junto do Tribunal de Contas, criado através da Lei nº54/2008, de 4 de setembro, deliberou em 4 de março de 2009 proceder ao levantamento dos riscos de corrupção e infrações conexas nas áreas da contratação pública e da concessão de benefícios públicos, através da aplicação de um questionário aos Serviços e Organismos da Administração Central, Regional e Local, direta ou indireta. Na sequência desta deliberação o CPC aprovou, em 1 de julho de 2009, a Recomendação $n^{0} 1 / 2009$ nos termos da qual os órgãos máximos das entidades gestoras de dinheiros, valores ou patrimónios públicos, fosse qual fosse a sua natureza, deviam elaborar Planos de Gestão de Riscos de Corrupção e Infrações Conexas (PGRCIC). O CPC considera que estes Planos constituem, além de um fator de gestão fundamental, um instrumento que permitirá aferir a eventual responsabilidade que ocorra na gestão de recursos públicos. A elaboração do PGRCIC por parte das entidades pode-se considerar como um contributo para aprofundar, atuar e reforçar o próprio sistema de controlo interno.

Neste sentido, é objetivo do presente estudo verificar os níveis de divulgação de informação de informação sobre o risco nos PGRCIC e respetivos relatórios de execução e, ainda, nos relatórios de gestão e contas anuais dos IP's públicos portugueses. E, também, verificar a eventual existência de relação entre as variáveis número de riscos/processos e as variáveis número de escolas e de cursos; população e massa monetária. A expetativa é de que esta relação se verifique.

O artigo está estruturado em cinco pontos. Após esta introdução, no ponto 2, é apresentada a revisão de literatura, com incidência nos conceitos de risco e sua identificação e gestão. Em seguida, trata-se o risco no setor público e menciona-se o normativo aplicável. Apresenta-se, ainda, alguns estudos sobre a divulgação de informação sobre o risco. Por fim, refere-se a questão da fraude e o papel do Tribunal de Contas de Portugal no combate e prevenção do risco. O ponto 3 refere-se à metodologia do estudo, incluindo o método de investigação, os objetivos, a população, a amostra, as fontes e forma de recolha dos dados. No ponto 4 apresenta-se e discute-se os resultados obtidos. Por último, no ponto 5 , expõem-se as conclusões, as limitações do estudo e algumas linhas de investigação futuras possíveis.

\section{Revisão de Literatura}

\subsection{O Risco}

A forma como as organizações, no exercício das suas atividades percecionam e gerem o risco é tida como essencial para permitir um cada vez maior controlo, tanto no setor privado como no setor público.

Segundo Beja (2004) um dos maiores desafios que as organizações enfrentam atualmente é, muitas vezes, caracterizado como a possibilidade de um determinado 
acontecimento poder ocorrer e gerar uma incerteza nos resultados e, por consequência, a assunção de riscos.

Existem diversos conceitos de risco, defendidos por diferentes autores, uns contemplando apenas aspetos negativos e outros, também, aspetos positivos potenciais. Por exemplo, Borge (2001 apud BEJA, 2004, p.81) considera que o "risco significa estar exposto à possibilidade de um resultado negativo" e Santos (2002 apud PENHA; PARISI, 2005, p.6) defende que "risco é a probabilidade de perda decorrente de um determinado evento". Enquanto Hill (2006, p.37) define o risco como "a incerteza em torno de eventos e resultados futuros. Trata-se da expressão da probabilidade e do impacto de um evento que pode influenciar a consecução dos objetivos de uma organização". A definição dada pela ISO/IEC GUIDE 73 (2009, p.2) foca, igualmente, a combinação da probabilidade e do impacto de um acontecimento. A Federation of European Risk Management Association (FERMA, 2003, p.3) refere que "o simples facto de existir atividade, abre a possibilidade de ocorrência de eventos ou situações cujas consequências constituem oportunidades para obter vantagens (lado positivo) ou então ameaças ao sucesso (lado negativo)." De acordo com a AS/NZS 4360 (2004 apud COOPER, 2007) o risco é a possibilidade de algo acontecer que terá um impacto sobre os objetivos e é medido em termos de consequências e probabilidades.

Silva (2009) refere que o risco pode ser interpretado de forma qualitativa, baseado num conceito intangível que dependerá da evidência dos critérios para a sua identificação, detecção e quantificação, apesar de que refere ao mesmo tempo a necessidade fundamental de se quantificar o risco como forma de facilitar a sua gestão. Porém, existem vários tipos de risco o que conduz à necessidade de diferentes estratégias de gestão de risco, podendo estas minimizar os impactos negativos e potenciar os aspetos positivos sobre os objetivos da organização. A sua identificação, usada por diferentes autores e organizações, não segue um padrão universal, embora existam algumas tipologias comuns.

A FERMA (2003) e, em certo sentido, o Instituto Brasileiro de Governança Corporativa (IBGC, 2007) consideram que a classificação dos riscos pode ter origem em fatores internos e externos à organização e assim, a sua tipologia inclui: riscos estratégicos, financeiros e operacionais. O Committee of Sponsoring Organizations of the Treadway Commission (COSO) II (2004) refere, também, os riscos estratégicos e operacionais e acrescenta os riscos de comunicação e de conformidade.

Assim, considera-se que a adequada identificação dos riscos é um passo fundamental para o exercício da atividade de gestão do risco. Segundo Shenkir e Walker (2007) são múltiplas as técnicas que auxiliam essa identificação (Brainstorming; inventários de acontecimentos; entrevistas e autoavaliação; workshops facilitadores; análise SWOT; questionários de risco e surveys de risco; análise de cenários; uso de tecnologias; entre outras).

Depois de os riscos serem identificados existe a necessidade da sua descrição, o que envolve a clarificação do âmbito, natureza e quantificação do risco; dos intervenientes; da tolerância/apetência ao risco; e do tratamento e mecanismos de controlo do risco (FERMA, 2003, p.7).

Os riscos identificados e descritos terão de ser hierarquizados de forma qualitativa ou quantitativa. No primeiro caso são classificados em termos da probabilidade de ocorrência e possível consequência (ameaças e oportunidades) e os fatores de graduação serão de estimativa fraca, média ou elevada. No segundo caso são usadas unidades de medida ( $€$, \#, ou outras) (FERMA, 2003; SHENKIR; WALKER, 2007). 
A gestão de risco tem vindo a merecer a atenção de diversos autores e organizações, mas ao longo dos anos é difícil encontrar uma definição universal. Moreau (2003, p.20) refere que a gestão do risco

pretende identificar e antecipar os acontecimentos, ações ou inações suscetíveis de afetar a execução da estratégia num determinado horizonte, definir as alternativas de resolução e garantir a escolha de uma opção otimizada, aplicar essa opção e controlar a eficácia da solução escolhida em relação às expetativas.

Para outros autores a gestão de risco baseia-se na criação de valor para o acionista, em função das avaliações do impacto dos riscos no valor das organizações (PADOVEZE, 2003 apud PENHA; PARISI, 2005; KROPP et al, 1999 e JESUS et al., 2002 apud ALVES, 2005).

$\mathrm{O} \operatorname{COSO}(2004$, p.2) refere que a gestão de risco consiste num

\begin{abstract}
processo contínuo que flui ao longo da organização; conduzido pelos profissionais em todos os níveis; aplicado à definição das estratégias e em toda a organização, em todos os níveis e unidades, e inclui a formação de uma visão de portfolio de todos os riscos a que ela está exposta; formulado para identificar acontecimentos em potencial, cuja ocorrência poderá afetar a organização, e para administrar os riscos de acordo com o seu apetite ao risco; capaz de propiciar garantia razoável para o Conselho de Administração e a Direcção executiva de uma organização; orientado para a realização de objetivos, em uma ou mais categorias distintas, mas dependentes.
\end{abstract}

Assim, importa gerir o risco tanto no setor privado como no setor público e desenvolver mecanismos de prevenção das ameaças e detecção de eventuais oportunidades futuras. Para que estes mecanismos funcionem de forma eficaz e eficiente têm sido desenvolvidos vários sistemas de gestão de risco por organizações de profissionais que têm vindo a ser criadas como, por exemplo:

- A Standards Austrália: criada em 1922, organização responsável pela publicação, em 1995, da primeira norma referente à gestão de risco "AS/NZS 4360" a qual sofreu ao longo dos anos diversos aperfeiçoamentos (Standards Austrália, 2012);

- A International Organization for Standardization (ISO): iniciou a sua atividade em 1947 dedicando-se à elaboração, produção e divulgação de normas internacionais e de outros documentos normativos. Emitiu em 2009 a "ISO 31000:2009 Risk Management - Principles and guidelines", documento passível de utilização por parte de qualquer tipo de entidade (ISO, 2012);

○ A FERMA: surgiu em 1974 e emitiu em 2002 a "Norma de Gestão de Riscos" (FERMA, 2012);

○ O COSO: constituído em 1985, tendo como objetivo identificar os fatores que levavam às fraudes nas demonstrações financeiras das organizações (COSO, 2012).

Ao longo dos anos, estas organizações têm vindo a criar modelos considerados de referência para a gestão do risco, na medida em que servem de motivação aos gestores das organizações pelo seu grau de exigência. Segundo Macieira (2008) estes modelos desempenham um papel importante na divulgação ampla para o reconhecimento de práticas eficazes e eficientes na gestão dos riscos. Embora não exista um único padrão para as melhores práticas de gestão de risco, todos estes processos seguem, em geral, os seguintes 
passos básicos: identificação, avaliação, análise, monitorização e comunicação dos riscos. Depois, repete-se todo o processo porque a gestão do risco tem de ser uma atividade contínua dado que a mudança obriga a essa dinâmica.

Para o setor público, identificar e determinar a forma mais adequada de gerir os riscos, constitui um enorme desafio. Hill (2006, p.40) refere que para uma boa gestão de riscos "exige-se esforço holístico, interdisciplinar e interministerial, que nos permita identificar uma ampla gama de riscos. Exige, também, um esforço permanente de sondagem do ambiente que nos permita detectar e transformar condições de risco".

Avila (2013) defende que o risco no setor público deve ser gerido tendo como objetivo principal o interesse público, ou seja, o dever de cuidar dos bens públicos dos cidadãos. $\mathrm{O}$ Estado é constantemente confrontado com riscos através das diversas funções que exerce, nomeadamente, na criação de condições para a estabilidade e prosperidade económica, na proteção do meio ambiente, na assistência social, na saúde e na educação.

O setor público é definido, de acordo com o n. 2 do artigo 82. ${ }^{\circ}$ da Constituição da República Portuguesa (CRP), como aquele que é "constituído pelos meios de produção cuja propriedade e gestão pertencem ao Estado ou a outras entidades públicas".

De acordo com Franco (1988 apud ARAÚJO 2005, p.8) o setor público nacional

\begin{abstract}
divide-se em Setor Público Administrativo (SPA) (atividade económica própria do Estado e outras entidades públicas não lucrativas que desempenham uma atividade pública segundo critérios não empresariais) e Setor Empresarial do Estado (SEE) (atividades dominadas exclusivamente por critérios económicos: produção de bens e serviços com o fim de gerar excedentes - lucros - dos proveitos sobre os custos).
\end{abstract}

Os IP's (objeto de estudo no presente trabalho) estão integrados no SPA, no subsetor da Administração Central (Fundos e Serviços Autónomos, Ministério da Educação). Têm, portanto, património próprio e aptidão para o gerir, alienar ou adquirir. Um dos aspetos relevantes neste grau de autonomia é o facto de alguns organismos terem receitas próprias provenientes de taxas ou de prestação de serviços (por exemplo, propinas).

Para Almeida (2005, p.43) a administração pública é "todo o aparelho do Estado, organizado e coordenado para a realização dos seus serviços, com o objetivo da satisfação das necessidades coletivas". Slomski (2003 apud SOARES; SCARPIN, 2010, p.32) afirma que é nesta administração que "mais deve estar presente a filosofia da accountability (dever de prestar contas), pois quando a sociedade elege os seus representantes espera que os mesmos ajam em seu nome, de forma correta, e que prestem contas de seus atos".

A aplicação das normas internacionais de contabilidade no setor público pode contribuir para uma maior transparência informativa por parte das organizações que o integram.

No perímetro do International Federation of Accountants Committee (IFAC), organismo internacional criado em 1977 com o objetivo de fortalecer a profissão, encontra-se o International Public Accounting Standards Board (IPSASB), entidade cujo objetivo é "servir o interesse público desenvolvendo normas contabilísticas de elevada qualidade e facilitando a centralização das normas nacionais e internacionais, aumentando assim a qualidade e uniformidade do relato financeiro em todo o mundo" (IFAC, 2012a). As International Public Accounting Standards (IPSAS) foram criadas para serem aplicadas internacionalmente e têm por base as International Accounting Standards (IAS) do International Accounting Standards Board (IASB). 
Atualmente mais de 80 países já adotaram as IPSAS ou encontram-se em processo de implementação destas normas, incluindo a Nova Zelândia; países do Sul da Ásia como a Tailândia, a Indonésia e a Malásia; países africanos como o Quénia e a Africa do Sul; países da América do Sul, como o Perú e o Brasil; e ainda países europeus como a Suíça, a Áustria e a Estónia (IFAC, 2012 b). Também, Organismos internacionais como a Organização do Tratado do Atlântico Norte, a Organização para a Cooperação Económica e o Desenvolvimento, a International Criminal Police Organization, a Comissão Europeia e a Organização dos Estados Americanos adotaram as IPSAS.

Entre as 32 normas emitidas pelo IPSASB, pela relação que têm com o "risco" destaca-se as seguintes:

- IPSAS 19 - Provisões, passivos contingentes e ativos contingentes (2003). Objetivos: "Definir provisões, passivos contingentes e ativos contingentes, identificar as circunstâncias em que as provisões devem ser reconhecidas, como devem ser mensuradas e as divulgações que devem feitas acerca das mesmas."

- IPSAS 21 - Valor Recuperável de Ativos não Geradores de Caixa (2004). Objetivos: "Prescrever os procedimentos que uma entidade aplica para determinar se um ativo não gerador de caixa está em imparidade e assegurar que as perdas por imparidade sejam reconhecidas."

- IPSAS 26 - Valor Recuperável de Ativos Geradores de Caixa (2008). Objetivos: "Prescrever os procedimentos que uma entidade aplica para determinar se um ativo gerador de caixa está em imparidade e assegurar que as perdas por imparidade sejam reconhecidas."

- IPSAS 28 - Instrumentos Financeiros: Divulgação e apresentação (2010). Objetivos: "Estabelecer princípios para a apresentação de instrumentos financeiros como passivo ou ativo líquido/património e para compensação de ativos financeiros e passivos financeiros.”

- IPSAS 29 - Instrumentos Financeiros: Reconhecimento e mensuração (2010). Objetivos: "Estabelecer princípios para reconhecer e mensurar ativos financeiros, passivos financeiros e alguns contratos de compra e venda de itens não financeiros."

- IPSAS 30 - Instrumentos Financeiros: Divulgação de informações (2010). Objetivos:

Exigir que a entidade divulgue nas suas demonstrações financeiras aquilo que permita que os usuários avaliem a: (a) Significância do instrumento financeiro para a posição financeira e para o desempenho da entidade; (b) Natureza e a extensão dos riscos resultantes de instrumentos financeiros a que a entidade está exposta durante o período e ao fim do período contabilístico e como a entidade administra esses riscos.

Assim, o IPSASB reconhece a importância da divulgação de informação sobre o risco, pois a IPSAS 28 (2010), a IPSAS 29 (2010) e a IPSAS 30 (2010) apresentam requisitos detalhados sobre o risco e a gestão do risco relacionados com o uso de instrumentos financeiros e a IPSAS 19 (2003), a IPSAS 21 (2004) e a IPSAS 26 (2008) tratam medidas contabilísticas de risco.

A contabilidade do setor público em Portugal tem vindo a sofrer várias reformas. Em 1990, com a Lei $\mathrm{n}^{\circ} 8 / 90$ de 20 de Fevereiro, iniciou-se o processo de reforma da Administração Publica, com o objetivo de o aproximar do sistema contabilístico privado (NOGUEIRA, 2006, p.6). 
Em 1997 foi publicado o Plano Oficial de Contabilidade Pública (POCP), emitido através do Decreto-Lei n. ${ }^{\circ}$ 232/97, de 3 de Setembro, tornando-se "um passo fundamental na reforma da Administração Financeira do Estado, bem como das contas públicas" (TEIXEIRA, 2009). O POC-Educação surgiu com a publicação da Portaria n. ${ }^{\circ} 794 / 2000$, de 20 de setembro, na sequência da anterior.

Nas últimas décadas tem-se assistido a um enorme esforço por parte das organizações internacionais, em encontrar normas, padrões ou procedimentos contabilísticos que ajudem ao desenvolvimento do setor público e privado com o objetivo de atingir e desenvolver as suas necessidades para uma melhor utilização das informações financeiras (MARCELO, 2007, p.35).

No que concerne à literatura sobre o tema referem-se, apenas, os seguintes estudos dada a escassez dos mesmos e, somente, por analogia.

Beattie, McInnes e Fearnley (2004) elaboraram um estudo sobre a divulgação de informação nos relatórios e contas de vinte e sete empresas de três setores de atividade. Verificaram que as informações prospetivas compreendiam apenas $813(6,6 \%)$ das 12.293 unidades de texto analisadas e que a informação prospetiva de "risco/ oportunidade" era de apenas 291 unidades de texto (2,4\% do total de divulgações). Além disso, dessas 813 divulgações sobre o futuro só $7 \%$ eram quantificadas. Por outro lado, outros autores, como Kajüter (2001), defendem que a existência de normas governamentais ajuda à divulgação de informação sobre o risco, sendo disso exemplo a Germany Accounting Standard (GAS) 5 "Risk Reporting" que exige às empresas alemãs a divulgação de informação sobre o risco desde o exercício que terminou em 31 de Dezembro de 2000. Woods e Reber (2003 apud WOODS, 2008) examinaram as divulgações de informação sobre o risco efetuadas por seis empresas alemãs e compararam os resultados com os de seis empresas do Reino Unido, para os anos de 2000 e 2001. Observaram um aumento de divulgações sobre o risco nas empresas alemãs pós GÁS 5 com a implicação de que a norma teve um efeito positivo sobre a comunicação de informação sobre o risco.

Quanto à relação entre a dimensão e o nível de divulgação de informação sobre o risco Linsley e Shrives (2006) e Kajüter (2006) verificaram que as grandes empresas tendiam a apresentar um nível mais elevado de divulgação de informação sobre o risco (WOODS, 2008).

Não especificamente sobre a divulgação de informação sobre o risco, mas incidindo nas determinantes da divulgação corporativa e social de entidades públicas, García-Sánchez, Aceituno e Domínguez (2013) estudaram 102 municípios de Espanha e concluíram que existia uma grande similitude na divulgação efetuada por esses municípios, relacionada com a estratégia, o perfil do Conselho e a informação económica, havendo forte correlação entre eles. Os municípios com maior nível de transparência económica, financeira e orçamental não se concentravam em questões sociais. Inversamente, a informação ambiental mostrava um maior grau de independência em relação à sua divulgação do que outros tipos de informação. Outras conclusões do estudo apontavam no sentido de que a dimensão do município tinha um impacto positivo nas divulgações de informação social e ambiental e a dimensão estava relacionada com o facto de quanto maior o município maior era o número de partes interessadas, o que incentivava à divulgação sobre a sua sustentabilidade. Do ponto de vista das normas e regras, os autores concluíram que os reguladores deviam emitir recomendações, orientações ou regras para aumentar a homogeneidade e transparência das informações das

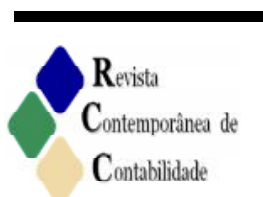

ISSN 2175-8069, UFSC, Florianópolis, v. 11, n. 24, p. 143-169, set./dez. 2014 
administrações locais. Concluíram, ainda, que uma maior visibilidade do município seria determinante de uma maior responsabilidade.

Cunha, Serra e Costa (2012, p. 703) efetuaram um estudo teórico em que salientavam a importância da elaboração dos PGRCIC e o caso dos Municípios em que a elaboração pela Associação Nacional dos Municípios Portugueses de um modelo tipo, poderá ter estado na origem de uma indesejável "excessiva homogeneização dos PGRCIC".

$\mathrm{O}$ risco de fraude é um tema que preocupa qualquer entidade, quer seja pública ou privada, com ou sem fins lucrativos.

\subsection{Fraude}

Em termos financeiros considera-se que existe fraude quando ocorrem atividades como corrupção, peculato, lavagem de dinheiro suborno ou extorsão (CIMA, 2008, p.7). Segundo a Association of Certified Fraud Examiners (ACFE, 2012, p.7) a fraude quando interna corresponde aos atos (fraudulentos) praticados pelos agentes internos da organização e divide-se em três categorias (ACFE, 2012, p.7):

- Má apropriação de ativos: refere-se à apropriação inadequada de numerário e/ou de outros ativos, como os inventários;

- Relatórios fraudulentos: podem ser financeiros ou não financeiros. Os primeiros respeitam a factos ligados à sobrevalorização (ex.: diferenças temporais, os rendimentos fictícios, os passivos e as despesas não declaradas, e as valorizações impróprias de ativos e das divulgações) e subvalorização (ex.: subestimação de rendimentos, passivos e despesas, assim como as valorizações impróprias de ativos e as diferenças temporais) de ativos e de rendimentos;

- Corrupção: inclui o uso de suborno e extorsão, o uso indevido de informação confidencial ou o conflito de interesses.

Em 2012, a ACFE publicou um Relatório às Nações revelando uma visão global da fraude. Os resultados apresentados na investigação efetuada pelos Certified Fraud Examiners (CFEs) basearam-se em 1.388 casos de fraude ocorridos em 100 países de 6 continentes. Estes casos deram origem a perdas totais na ordem dos 215 milhões de dólares o que, em termos médios por caso, resulta num valor de, aproximadamente, 157 mil dólares. O relatório aponta não só quais os setores envolvidos no estudo mas, também, o número de casos por cada um deles e relaciona este número com as perdas médias de fraude por caso. Verificou-se que existiam setores com elevado peso percentual de casos (Serviços financeiros e bancos, 16,7\%; Industria, 10,4\%; e Estado e Administração Publica, 10,3\%) mas com perdas médias por caso não tão significativas (respetivamente, 232, 200, e 100 mil dólares). Inversamente, existiam setores com baixo peso percentual de casos, mas que tinham um valor significativo de perdas médias por caso (Minas, 0,7\%/\$500 mil; Imobiliário, 2\%/\$375 mil; e Construção 3,4\%/\$300 mil).

Relativamente aos resultados obtido pela ACFE considera-se de salientar, pela relação com o presente estudo, o facto de o setor Estado e Administração Publica (EAP) adicionado ao setor da Educação representarem um valor percentual de 16,7\% com uma perda média por caso de 136 mil dólares, o que os destacaria no contexto global. Por outro lado na comparação entre estes dois setores verificaram-se alterações na ordem da importância dos cenários de fraude. A corrupção no EAP aparecia com maior número de casos, enquanto na Educação surgia na terceira posição com um diferencial de $8,5 \%$. A faturação surgia nos dois setores, 
também, como importante fonte de fraude, com variação entre eles de 3,8\%, sendo que no setor Educação surgia em $1^{\circ}$ lugar e no EAP surgia em segundo lugar. É de realçar que, em ambos os setores, os cenários ligados a atos de consequências financeiras, nomeadamente, faturação, reembolso de despesas, lista de pagamentos, "luvas", furto de caixa e demonstrações financeiras, representavam 50\% ou mais dos casos de fraude (ACFE, 2012)

Sendo a corrupção considerada uma barreira para o desenvolvimento económico, social e político tem merecido, cada vez mais, a atenção de várias organizações e diversos autores. Segundo Tanzi (1998, p.564) a definição de corrupção usada pelo Banco Mundial é a mais comum e refere-se ao "abuso de poder público em benefício próprio".

A Transparency Internacional (TI) é uma organização não-governamental sem fins lucrativos, fundada em 1993, que visa elevar os níveis de transparência na Administração Pública a nível global. Esta Organização, desde 1995, publica anualmente o Índice de Perceção da Corrupção (IPC), classificando os países em termos de "grau de perceção da existência de corrupção entre os funcionários públicos e políticos". Nos últimos cinco anos este Índice tem incidido sobre mais de $90 \%$ do número total de nações soberanas do mundo. Atualmente, Portugal mantém-se no $32^{\circ}$ lugar global do IPC e, em relação à Europa, ocupa o $18^{\circ}$ lugar (TI, 2009).

Em Portugal, o contacto com a TI é efetuado através da Associação Transparência e Integridade, criada em 2010, com o objetivo principal de coordenação e apoio a um conjunto de organizações da sociedade civil a nível global que combatem a corrupção em território nacional. Edita periodicamente uma análise detalhada da situação em Portugal que designa por Sistema Nacional de Integridade (SNI). Em 2012, o SNI referia que em relação a Portugal, os dados de acordo com o Global Integrity Report, pareciam ser contraditórios no combate à corrupção, tendo em conta que o país possuiria um dos melhores conjuntos institucionais e legislativos, todavia com "fracos resultados demonstrados" (SNI, 2012, p.23). Este Sistema integra, também, a avaliação das principais instituições públicas e atores nãoestatais do sistema nacional de governação, entre os quais destaca-se a Administração Pública, o Tribunal de Contas e Organismos Especializados de Combate à Corrupção.

Com a intensificação das relações internacionais e a globalização a corrupção atingiu uma escala mundial. Para tentar minimizar este fenómeno foram criados organismos internacionais especializados no combate e prevenção da corrupção, também denominados por Agências Anti-Corrupção (SNI, 2012).

A Organização das Nações Unidas (ONU) desenvolveu, em 31 de outubro de 2003, a Convenção das Nações Unidas contra a Corrupção (mais conhecida como a Convenção de Mérida) que, de acordo com o $\operatorname{art}^{\mathrm{o}} 1$, tem como objeto

a) Promover e reforçar as medidas que visam prevenir e combater de forma mais eficaz a corrupção; $b$ ) Promover, facilitar e apoiar a cooperação internacional e assistência técnica em matéria de prevenção e de luta contra a corrupção, incluindo a recuperação de ativos; c) Promover a integridade, a responsabilidade e a boa gestão dos assuntos e bens públicos.

Em Portugal esta Convenção só foi aprovada em 2007, através da Resolução da Assembleia da Republica ${ }^{\circ} 47 / 2007$ que dispõe no seu art. ${ }^{\circ} 3^{\circ}$ que a "entidade responsável pelo auxílio a outras Partes a desenvolver e aplicar medidas específicas para prevenir a corrupção é a Direcção-Geral da Política de Justiça do Ministério da Justiça." Na aplicação da Resolução ter-se-á verificado, ao longo do tempo, o incumprimento do seu $\operatorname{art}^{\circ} 6$ no tocante à

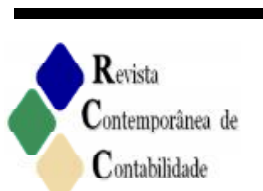

ISSN 2175-8069, UFSC, Florianópolis, v. 11, n. 24, p. 143-169, set./dez. 2014 
inexistência de um órgão especializado no combate à corrupção. Assim foi criado pela Lei ${ }^{\circ}$ 54/2008 de 4 de setembro da Assembleia da Republica, o Conselho de Prevenção da Corrupção (CPC). O CPC “é uma entidade administrativa independente que funciona junto do Tribunal de Contas e tem como fim desenvolver, nos termos da lei, uma atividade de âmbito nacional no domínio da prevenção da corrupção e infrações conexas" (art. ${ }^{\circ} 1$ da Lei 54/2008).

As competências do CPC são, entre outras, as de recolher informações, acompanhar a aplicação dos instrumentos jurídicos e das medidas administrativas e dar pareceres sobre a elaboração de instrumentos normativos, todas estas competências na prevenção e combate da corrupção e crimes conexos na administração pública ( $\operatorname{art}^{\circ} 2^{\circ}$ da Lei 54/2008). Na sequência da Recomendação $n^{0} 1 / 2009$ de 1 de julho, emitida pelo CPC e tendo em conta as indicações apresentadas em normas internacionais para a gestão do risco (ex.: FERMA, 2003; COSO II, 2004), o Tribunal de Contas através da sua Direcção Geral (DGTC) e por Despacho n ${ }^{\circ}$ 36/2009 - GP, de 30 de outubro, aprovou o PGRCIC que pretende ser mais amplo que o mínimo recomendado pelo CPC. Este Plano prevê que

os órgãos máximos das entidades gestoras de dinheiros, valores ou patrimónios
públicos, seja qual for a sua natureza, devem, no prazo de 90 dias, elaborar planos de
gestão de riscos e infrações conexas, contendo os seguintes elementos: a)
Identificação, relativamente a cada área ou departamento, dos riscos de corrupção e
infrações conexas; b) Com base na identificação dos riscos, identificação das
medidas adotadas que previnam a sua ocorrência (por exemplo, mecanismos de
controlo interno, segregação de funções, definição prévia de critérios gerais e
abstratos, designadamente na concessão de benefícios públicos e no recurso a
especialistas externos, nomeação de júris diferenciados para cada concurso,
programação de ações de formação adequada, etc.); c) Definição e identificação dos
vários responsáveis envolvidos na gestão do plano, sob a direção do órgão dirigente
máximo; d) Elaboração anual de um relatório sobre a execução do plano (CPC,
2009).

Com estrutura idêntica à do guião do CPC para a sua elaboração, o Plano institui "diretrizes sobre a prevenção de riscos de gestão, incluindo os riscos de corrupção e infrações conexas, identifica os critérios de risco adotados, e define as funções e responsabilidades na gestão e coordenação das atividades da DGTC" (TRIBUNAL DE CONTAS, 2009).

De acordo com o Guião para a elaboração dos PGRCIC (2009), o CPC sugere a seguinte composição:

Parte I - Atribuições da entidade, organograma e identificação dos responsáveis Caracterização genérica das atribuições da entidade (a razão da sua existência) e da estrutura orgânica que apresenta, com identificação dos responsáveis.

Parte II - Identificação dos riscos de corrupção e infrações conexas - Tendo em conta as funções da entidade, devem ser identificados e caracterizados por unidade orgânica os respetivos potenciais riscos de corrupção e infrações conexas. Estes riscos devem ser classificados segundo uma escala de risco elevado, risco moderado e risco fraco, em função do grau de probabilidade de ocorrência (elevado, moderado ou fraco). Por sua vez, este grau de probabilidade deverá ser aferido a partir da própria caracterização de cada uma das funções.

Parte III - Medidas preventivas dos riscos - Identificados os riscos, devem ser indicadas as medidas que previnam a sua ocorrência, tais como mecanismos de controlo interno, segregação de funções, declarações de interesses, definição prévia de critérios gerais e abstratos de concessão de benefícios públicos, criação de gabinetes de auditoria interna em especial nas entidades de maior dimensão, controlo efetivo das situações de acumulações de funções públicas com atividades 
privadas e respetivos conflitos de interesses. Esta é uma enumeração meramente exemplificativa.

Parte IV - Estratégias de aferição da efetividade, utilidade, eficácia e eventual correção das medidas propostas - Os Planos de Prevenção de Riscos de Corrupção e Infrações Conexas são instrumentos de gestão dinâmicos, pelo que devem ser acompanhados na sua execução, elaborando-se, pelo menos anualmente, um relatório de execução e reflectindo-se sobre a necessidade da sua atualização.

De acordo com o CPC (2009), a elaboração dos PGRCIC deve estar a cargo das próprias entidades e organismos públicos, pois são eles os especialistas das situações diárias que acorrem em cada atividade. Para verificar da elaboração e execução dos Planos, o CPC prevê visitas às instituições públicas. Assim, no seu Relatório de Atividades de 2012 o CPC referia a existência de um acompanhamento da aplicação da Recomendação $n^{\circ} 1 / 2009$ de 1 de julho em 19 entidades entre as quais um IP (IP de Santarém). A escolha das entidades é feita aleatoriamente. Estas visitas, segundo o CPC, têm como objetivo verificar diversos aspetos, nomeadamente, quem interveio na sua elaboração, quais os critérios, que matérias abrangem e se são suficientes. Também

\begin{abstract}
procuram determinar como foram identificados os riscos, as medidas de prevenção propostas, os procedimentos da respetiva adequação, a existência ou não de segregação de funções, como se processa o acompanhamento da aplicação do plano e a elaboração do correspondente relatório, como estão definidas as atualizações periódicas e quais os primeiros impactos (internos e externos) da aplicação do plano elaborado pela entidade, solicitando os relatórios de execução e acompanhamento, caso existam (CPC, 2012).
\end{abstract}

No presente estudo e por analogia com o estudo de García-Sánchez, Aceituno e Domínguez (2013), foca-se a informação sobre o risco (em substituição da informação social e ambiental) e os IP's públicos portugueses (em vez de municípios espanhóis), esperando-se encontrar resultados semelhantes em relação à temática da divulgação de informação sobre o risco.

\title{
3 Metodologia
}

A presente pesquisa, em termos de abordagem do problema, é de caráter qualitativo e quantitativo, pois procura, por um lado descrever as informações sobre o risco contidas nos documentos em análise e, por outro, eventuais relações entre variáveis. Atendendo ao primeiro objetivo procura-se resposta para as seguintes questões:

○ Estão os PGRCIC dos IP's portugueses em conformidade com a Recomendação $\mathrm{n}^{\mathrm{o}} 1 / 2009$ de 1 de julho do CPC?

- Será a sua implementação e monitorização efetuada de acordo com a Recomendação $\mathrm{n}^{\mathrm{0}} 1 / 2009$ de 1 de julho do CPC?

E, atendendo ao segundo objetivo, procura-se identificar relações entre as variáveis selecionadas, visando responder às seguintes questões:

- Caso existam, quais as variáveis que influenciam a quantidade de riscos divulgada pelos IP's?

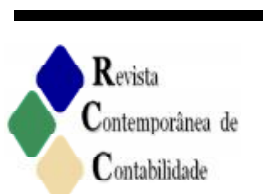

ISSN 2175-8069, UFSC, Florianópolis, v. 11, n. 24, p. 143-169, set./dez. 2014 
○ Caso existam, quais as variáveis que influenciam a quantidade de processos dos IP's?

\subsection{População e Amostra}

No presente estudo, a população é constituída pelos quinze IP's Públicos portugueses por se tratar de instituições de grande importância para as regiões onde se inserem. Funcionam como pólos de desenvolvimento, não só pela qualificação e formação mas, também, pelo apoio dado às empresas sedeadas nas regiões prestando serviços tais como, elaboração de estudos e desenvolvimento de projetos (CCISP, 2010).

A amostra, considerada representativa, inclui treze dos quinze IP's Públicos, por os Planos do IP Bragança e o do IP Portalegre não estarem disponíveis. Impõe-se, então, a caracterização e contextualização dos Institutos.

Em Portugal, a Rede do Ensino Superior Politécnico foi criada em 1979 através do Decreto-Lei $\mathrm{n}^{\mathrm{o}}$ 513-T/79, de 26 de dezembro, onde o termo "ensino superior de curta duração" foi substituído por "ensino superior politécnico". Posteriormente alterado pela Lei $\mathrm{n}^{\circ}$ 29/80, de 28 de julho (URBANO, 2008:4). Também, em 1979, através do Decreto-Lei no $513-$ $\mathrm{T} / 79$ de 26 de dezembro, foi criado o CCISP, entidade que representa e coordena os estabelecimentos públicos de ensino superior politécnico. Este papel foi aprovado legalmente por via do Decreto-Lei n ${ }^{\circ}$ 344/93 de 1 de outubro.

Em 1986, a Lei de Bases do Sistema Educativo (Lei 46/86 de 14 outubro) veio determinar, por definitivo, a natureza do Ensino Superior, de acordo com o n 1 do $\operatorname{art}^{\mathrm{o}} 11$, "O ensino superior compreende o ensino universitário e o ensino politécnico" e com o objetivo de "proporcionar uma sólida formação cultural e técnica de nível superior, desenvolver a capacidade de inovação e de análise crítica e ministrar conhecimentos científicos de índole teórica e prática e as suas aplicações com vista ao exercício de atividades profissionais" $\left(\mathrm{n}^{\circ} 4\right.$ do $\left.\operatorname{art}^{0} 11\right)$.

A Tabela 1 apresenta alguns dados que ajudam à caracterização dos IP's públicos portugueses.

Em Portugal, os primeiros IP's foram criados em 1979 e o ultimo em 1996, no distrito de Braga. Estão distribuídos por 14 distritos e somavam, em 2010, um total de 75 escolas. O maior número de escolas verificava-se no IP de Lisboa com um total de oito, pertencendo o menor número ao IP do Cavado e do Ave com apenas duas escolas. Em termos médios cada Instituto integrava cerca de cinco escolas. Os 15 IP's ofereciam um total de 943 cursos conferentes de grau, ou seja, de licenciaturas e mestrados. O Instituto com o número mais elevado de licenciaturas era o IP do Porto com 84, encontrando-se o IP da Guarda em último neste ranking, com 22 licenciaturas. Em termos médios cada Instituto oferecia, aproximadamente, 41 licenciaturas. No que respeita aos cursos de mestrado o IP do Porto aparecia em primeiro lugar com 44, estando o IP de Beja em último com um total de oito. Em termos médios cada Instituto oferecia, aproximadamente, 24 mestrados.

Como se verifica, em 2010 o total de alunos nos IP's públicos portugueses ascendia a 105.431, pertencendo mais de 50\% aos IP's de Coimbra, Leiria, Lisboa e Porto. Este último apresentava o número mais elevado com um total de 17.121 alunos, enquanto o IP de Portalegre apresentava o menor número de alunos, contando com 2.726. O número médio de alunos entre os Institutos foi de 7.029. 


\begin{tabular}{|c|c|c|c|c|c|c|c|c|c|}
\hline \multirow[b]{2}{*}{ IP's } & \multirow[b]{2}{*}{ Data } & \multirow[b]{2}{*}{$\begin{array}{l}\text { Esco } \\
\text { Las }\end{array}$} & \multicolumn{2}{|c|}{$\begin{array}{c}\text { Cursos conferentes de } \\
\text { grau }\end{array}$} & \multirow[b]{2}{*}{ Alunos } & \multirow[b]{2}{*}{$\begin{array}{c}\text { Docen } \\
\text { tes }\end{array}$} & \multirow[b]{2}{*}{$\begin{array}{c}\text { Não } \\
\text { docen } \\
\text { tes }\end{array}$} & \multicolumn{2}{|c|}{ Massa Monetária } \\
\hline & & & $\begin{array}{l}\text { Licen } \\
\text { ciaturas }\end{array}$ & $\begin{array}{c}\text { Mestra } \\
\text { dos }\end{array}$ & & & & $\begin{array}{l}\text { Despesas } \\
\text { de } \\
\text { funcionam } \\
\text { ento }(\mathrm{M} € \text { ) }\end{array}$ & $\begin{array}{l}\text { Receitas } \\
\text { (M€) }\end{array}$ \\
\hline Beja & 1979 & 4 & 36 & 8 & 3.241 & 3.241 & 163 & 16.363 & 19.784 \\
\hline Bragança & 1979 & 5 & 44 & 32 & 7.434 & 7.434 & 297 & 30.483 & 33.670 \\
\hline $\begin{array}{l}\text { Castelo } \\
\text { Branco }\end{array}$ & 1979 & 6 & 31 & 22 & 4.566 & 4.566 & 267 & 23.148 & 24.556 \\
\hline $\begin{array}{l}\text { Cávado e } \\
\text { do Ave }\end{array}$ & 1996 & 2 & 25 & 15 & 3.630 & 3.630 & 46 & 7.290 & 7.577 \\
\hline Coimbra & 1979 & 6 & 52 & 40 & 11.334 & 11.334 & 430 & 43.515 & 49.436 \\
\hline Guarda & 1979 & 4 & 22 & 10 & 3.300 & 3.300 & 181 & 15.654 & 17.087 \\
\hline Leiria & 1980 & 5 & 72 & 31 & 12.097 & 12.097 & 474 & 45.441 & 46.451 \\
\hline Lisboa & 1979 & 8 & 55 & 41 & 14.559 & 14.559 & 453 & 68.604 & 85.515 \\
\hline Portalegre & 1980 & 4 & 24 & 9 & 948 & 948 & 166 & 13.698 & 14.702 \\
\hline Porto & 1980 & 7 & 84 & 44 & 17.121 & 17.121 & 444 & 75.286 & 131.567 \\
\hline Santarém & 1979 & 5 & 32 & 24 & 4.227 & 4.227 & 193 & 20.749 & 21.766 \\
\hline Setúbal & 1979 & 5 & 30 & 19 & 6.696 & 6.696 & 195 & 29.360 & 40.239 \\
\hline Tomar & 1987 & 3 & 28 & 11 & 3.513 & 3.513 & 174 & 15.650 & 16.338 \\
\hline $\begin{array}{l}\text { Viana do } \\
\text { Castelo }\end{array}$ & 1980 & 5 & 30 & 30 & 4.261 & 4.261 & 164 & 21.491 & 22.097 \\
\hline Viseu & 1979 & 6 & 43 & 21 & 6.726 & 6.726 & 266 & 26.726 & 38.632 \\
\hline Total & - & 75 & 608 & 335 & 105.431 & 105.431 & 3.913 & 453.458 & 569.416 \\
\hline
\end{tabular}

Fonte: Dados da pesquisa.

No que respeita aos funcionários docentes e não docentes totalizavam 11.725, destacando-se o IP do Porto com maior número de docentes (1.416) e o IP de Leiria com o maior número de não docentes (474). Com menor número de docentes (178) e não docentes (46) estava o IP do Cávado e do Ave. Em termos médios cada Instituto apresentava 782 funcionários.

As despesas de funcionamento totalizavam 453.458 M€, com um máximo de 75.286 M€ no IP do Porto e um mínimo de 7.290 M€ no IP do Cávado e do Ave. Em termos médios houve um gasto de funcionamento por Instituto de 30.230 M€. O total das receitas dos quinze Institutos ascendeu a 569.416 M€ com um máximo de 131.567 M€ no IP do Porto e um mínimo de 7.577 M€ no IP do Cávado e do Ave. A média da receita representava 37.961 M€ por Instituto. As receitas dos Institutos resultam de transferências do Estado e de receitas próprias (propinas e outras receitas), necessárias para sustentar as despesas de funcionamento (despesas com pessoal / despesas correntes de funcionamento / despesas de capital).

Salienta-se, ainda, o elevado nível de dispersão nos indicadores analisados.

\subsection{Fonte e recolha dos dados}

No site do CCISP foram obtidos os dados relativos ao número de escolas; cursos; estudantes; docentes e não docentes; e, ainda, os dados relativos às despesas de funcionamento e em edifícios e outras construções; e ao total de receitas. Depois, foram recolhidos os PGRCIC, referentes a 2009/2010, resultando dai dados sobre o a quantidade de

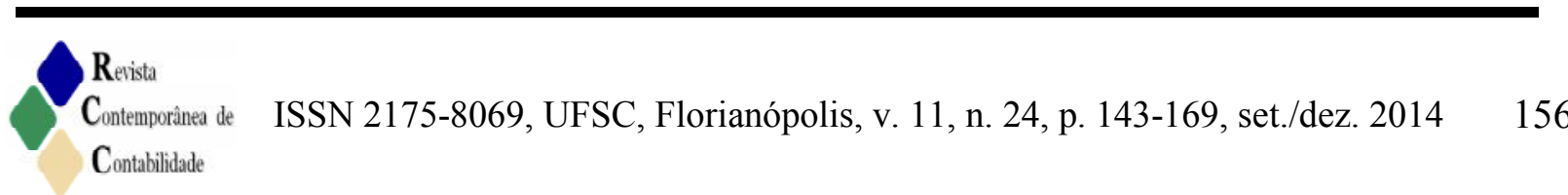


riscos previstos e os procedimentos. Inicialmente pretendia-se analisar os relatórios de execução dos PGRCIC e os relatórios de gestão e contas dos IP's do período. Porém, não foi possível recolher esses documentos, pois apenas um IP divulgava os primeiros e seis IP's divulgavam integralmente os segundos. Desta forma, ficou inviabilizada a verificação, por um lado, da execução dos PGRCIC e, por outro do nível de divulgação de informação sobre risco aplicando a análise de conteúdo sintática.

Assim, os documentos objeto de análise quanto ao risco restringiram-se aos PGRCIC dos IP's da amostra. Estes documentos devem ser entendidos como instrumentos de gestão estratégica e operacional no sentido de identificar, medir, acompanhar e controlar os riscoschave que a organização enfrenta na prossecução da sua missão e objetivos (TRIBUNAL DE CONTAS, 2009). Este Plano deve obedecer aos princípios do interesse geral, nomeadamente, "da prossecução do interesse público, da igualdade, da proporcionalidade, da transparência, da justiça, da imparcialidade, da boa fé e da boa administração" (CPC, 2009). Para Cunha, Serra e Costa (2012, p.703) a "implementação dos PGRCIC" constitui "um marco decisivo para a prevenção e combate da corrupção”. Segundo o CPC (2009), mais importante do que elaborar um PGRCIC é implementá-lo e monitorizá-lo, uma vez que este documento deve constituir um instrumento de prevenção de riscos de gestão, incluindo os riscos de corrupção e infrações conexas, em constante melhoramento. Para tal, a Recomendação n. ${ }^{\circ} 1 / 2009$ refere que deve ser elaborado e entregue, anualmente, um relatório sobre a execução do PGRCIC. Este relatório deverá mencionar se o PGRCIC foi ou não cumprido, identificar as medidas adotadas e por adotar; descrever os riscos eliminados, reduzidos, e ainda, existentes, bem como identificar novos riscos e propor melhorias para o PGRCIC.

\section{Análise dos Resultados}

Depois da agregação dos dados relativos aos PGRCIC de cada um dos IP's da amostra procedeu-se à respetiva análise. $\mathrm{O}$ facto de as variáveis consideradas serem de natureza quantitativa permitiu o cálculo das medidas estatísticas julgadas importantes para o problema em análise.

\subsection{Análise Descritiva}

Assim, efetuou-se a análise descritiva focada nos seguintes dados: tipos de risco; identificação e hierarquização dos riscos; número total de riscos, de processos e de medidas/procedimentos de prevenção.

Em relação aos tipos de risco verificou-se que todos os IP's analisados seguiam a terminologia usada no Código do Processo Administrativo e no Código Penal. Dessa tipologia destacam-se, pela sua existência na maioria dos processos, os seguintes riscos: pagamento indevido; abuso de poder; corrupção ativa e passiva para ato ilícito; peculato; favorecimento de candidatos/alunos; tráfico de influências; participação económica em negócio; apropriação indevida de bens; falsificação de documentos; falsas declarações; deslocação e serviço público sem autorização; violação dos deveres legais do Estatuto Disciplinar e; intervenção em situação de impedimento.

Quanto à identificação e hierarquização dos riscos verificou-se que os IP's de Setúbal, Viseu e Leiria divulgavam esta informação, referindo que os riscos eram determinados pela 
aplicação de critérios entre os quais "a avaliação, o histórico de ocorrências, o nível de informatização/intervenção manual em cada processo, a existência de segregação de funções e a análise por área, dos sistemas de controlo existentes" (IP Setúbal, PGRCIC 2009). A probabilidade de ocorrência e a gravidade das consequências foram critérios para identificação dos riscos no IP de Leiria. O IP de Viseu não utilizava o critério de identificação mas pressupunha que existiam potenciais riscos de corrupção e infrações conexas, partindo daí para a identificação das áreas potencialmente expostas a esses riscos. Os restantes IP's da amostra não divulgavam nos seus Planos as formas de identificar os riscos. O gráfico 1 evidencia o número de riscos identificados por cada um dos IP's.

\section{Gráfico 1 - No total de riscos identificados}

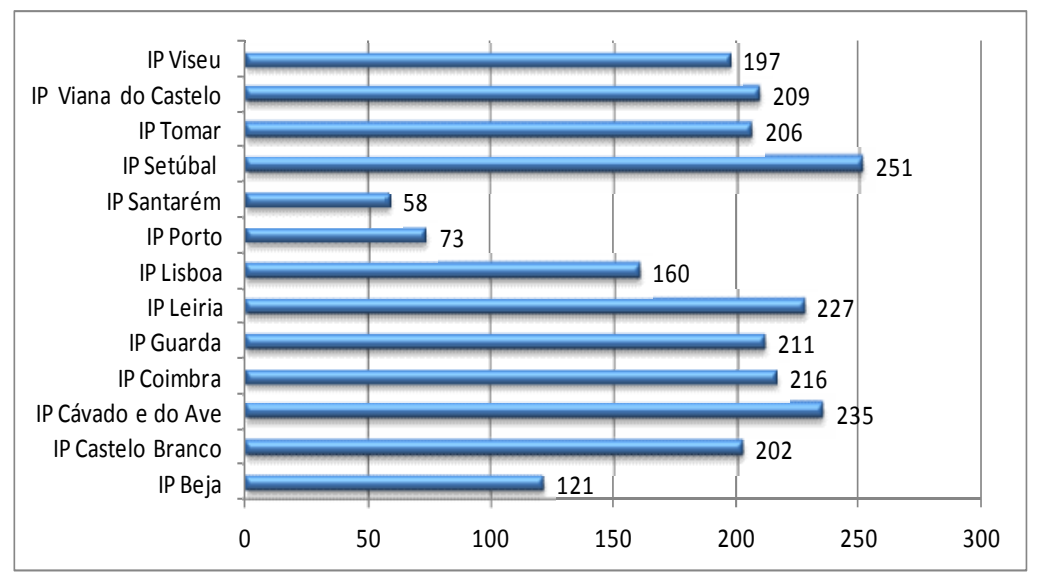

Fonte: Dados da pesquisa.

Verifica-se um total de 2.368 riscos identificados. O IP de Setúbal (251) e o IP de Santarém (58) identificaram, respetivamente, o maior e o menor número de riscos.

Além desta análise global, analisaram-se os riscos identificados por cada Instituto e por área, conforme $\mathrm{n}^{\mathrm{o}} 1.1$ da alínea a) da Recomendação $\mathrm{n}^{\circ} 1 / 2009$ do CPC. Verificou-se que as áreas que os Institutos consideravam mais suscetíveis de geração de riscos foram: estudantes/serviços académicos $(24,58 \%)$; contratação pública $(24,37 \%)$; património $(16,64 \%)$; recursos humanos/pessoal/funcionários $(16,26 \%)$; e receita/financeira $(12,54 \%)$. Os menos suscetíveis foram: propriedade intelectual e patentes $(3,25 \%)$; atribuição de benefícios $(1,39 \%)$; segurança informática/outros serviços (0,55\%); e fundo de maneio $(0,42 \%)$.

Relacionando a tipologia dos riscos utilizada pela FERMA (2003) foi possível verificar que os IP's evidenciavam riscos estratégicos (património, propriedade intelectual e patentes); financeiros (receita/financeira e fundo de maneio); operacionais (segurança informática/outros serviços); e perigos (estudantes/serviços académicos, recursos humanos, atribuição de benefícios, contratação pública). Estes riscos podiam ter origem interna (receita/financeira; propriedade intelectual e patentes; segurança informática/outros serviços; fundo de maneio), externa (contratação pública) ou interna/externa (estudantes/serviços académicos; património; recursos humanos; atribuição de benefícios).

Após a identificação dos riscos, os Planos devem apresentar a hierarquização dos mesmos de acordo com o Despacho n⿳36/2009 - GP do Tribunal de Contas, no seu anexo II. Esses critérios são classificados em função dos graus da probabilidade da ocorrência e da gravidade da consequência como baixa, média ou alta. Verificou-se que apenas dois IP's 
(Setúbal e Leiria) faziam uma referência introdutória à forma de hierarquizar os riscos identificados, os restantes não referiam os critérios adotados.

Em relação à análise sobre a identificação e a hierarquização dos riscos e em síntese, verifica-se que os 13 Institutos estudados efetuaram e divulgaram essa identificação mas que, apenas, cinco (IP Lisboa; IP Porto; IP Santarém; IP Setúbal; IP Viseu) efetuaram a respetiva hierarquização. Não seguiram, assim, integralmente, o Despacho n³6/2009 - GP no seu Anexo II, ponto C. Este ponto refere, tal como a FERMA (2003), que a graduação do risco deverá ter em conta a probabilidade da ocorrência e a gravidade da consequência. Ou seja, a cada risco identificado deve ser atribuída uma classificação com base nestes dois critérios. Cada risco deve ser estimado e avaliado numa matriz com base nos princípios enunciados para a sua graduação, sendo classificados como reduzido, moderado ou elevado, respetivamente, a cor verde, amarela e vermelha.

Verificou-se que entre os cinco Institutos que divulgaram a hierarquização dos riscos, quatro (IP Lisboa; IP Porto; IP Setúbal; IP Viseu) utilizavam somente o grau de probabilidade de ocorrência e um (IP de Santarém) não utilizou qualquer dos critérios, utilizando em vez disso, o critério do risco inerente e o do risco de controlo. Verificou-se, também, que existindo riscos comuns nos IP's o seu grau de probabilidade de ocorrência diferia, por exemplo, para a área de contratação pública, processo de renovação de contratos, risco de favorecimento de fornecedores. Enquanto o IP de Lisboa e o IP de Viseu consideraram um grau de probabilidade de ocorrência elevado, o IP do Porto e o IP de Setúbal consideraram um grau médio e o IP de Santarém considerou um grau reduzido. Desta forma, constata-se a existência de diferenças de hierarquização dos riscos entre os cinco Institutos que a elaboram e que apontam claramente para graus de probabilidade de ocorrência do mesmo risco bastante distintas. Quando se analisa as demais áreas e nos mesmos cinco IP's, encontra-se a mesma dispersão na hierarquização.

Da análise dos processos (Gráfico 2) verificou-se que todos os IP's da amostra identificaram os riscos especificando-os por área. Por exemplo: para a área de recursos humanos apresentaram os processos de concurso para pessoal docente, não docente e bolseiros; remunerações; e seleção de candidatos, enquanto para a área de contratação pública podiam ter os processos de verificação de bens fornecidos; aquisição de bens e serviços por ajusto direto simplificado; e intervenção em processos de contratação enquanto membro de júri (IP de Setúbal, 2009). Estes exemplos são de certa forma comuns aos restantes IP's.

\section{Gráfico 2 - No total de processos por IP}

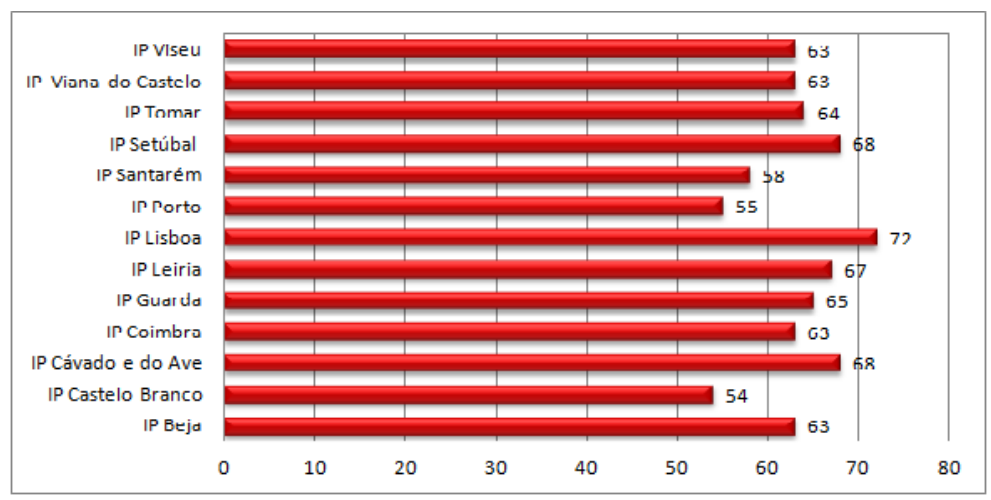

Fonte: Dados da pesquisa. 
Verifica-se que o número de processos de cada Instituto variava entre 54 e 72, respectivamente, do IP de Castelo Branco e do IP de Lisboa.

Depois da enumeração dos processos e da identificação dos riscos associados, compete a cada Instituto determinar quais as medidas de prevenção a adotar (CPC, 2009). O ponto 1.1 da alínea b) da Recomendação $n^{0} 1 / 2009$ do CPC refere que outro dos elementos importantes a ser identificado nos Planos são as medidas adotadas que previnam a sua ocorrência, com base nos riscos identificados. Assim, cabe a cada IP determinar quais as medidas a colocar em prática para prevenir ou para minimizar esses mesmos riscos, no caso de ser impossível evitálos. As medidas foram previstas para cada área ou departamento, tal como com os riscos e os processos. Dessa análise verificou-se que todos os IP's estudados identificavam as suas medidas (embora alguns IP's as tratassem como procedimentos) de prevenção de ocorrência. Os IP's apresentavam algumas medidas comuns. No entanto, a sua heterogeneidade era maior do que em relação às áreas.

A título de exemplo, dada a diversidade de áreas e de medidas existentes nos Planos salienta-se as que se referem à área da receita/financeira e ao processo de pagamento de propinas. Neste processo mais de $60 \%$ dos Institutos indicavam o "reforço de medidas de controlo interno" e/ou a "verificação periódica e aleatória" como medida preventiva (IP's de Braga, Beja, Castelo Branco, Cávado e do Ave, Coimbra, Leiria, Lisboa, Santarém, Tomar, Viana do Castelo e Viseu), tendo o IP de Setúbal indicado como medida preventiva a "geração de referências multibanco para pagamento on-line".

O gráfico 3 evidencia a relação entre o número de processos e o número de medidas preventivas divulgados.

\section{Gráfico 3: $\mathbf{N}^{0}$ de processos / $\mathbf{n}^{0}$ de medidas preventivas}

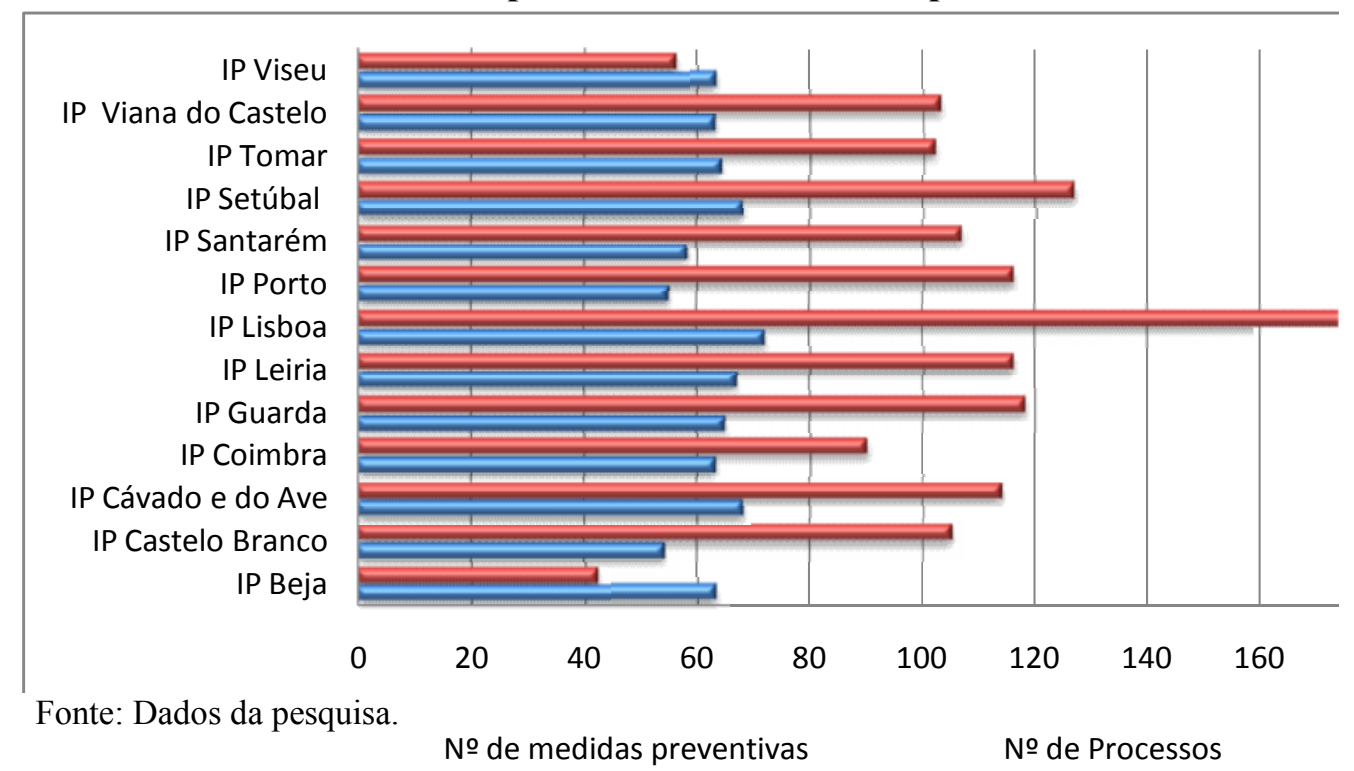

Na relação do número dos processos com o número de medidas preventivas existentes nos Institutos verifica-se que na sua maioria (exceto o IP de Beja e o IP de Viseu), estas medidas eram superiores aos processos identificados. Verifica-se, ainda, que entre os Institutos estudados existia uma discrepância em termos das situações de números de processos semelhantes e das consequentes medidas preventivas. O IP de Lisboa e o IP do Cávado e do Ave com 72 e 68 processos, respetivamente, apresentavam um número de 
medidas preventivas de 176 e 114, respetivamente. O IP de Coimbra, o IP de Viana do Castelo e o IP de Viseu apresentavam igual número de processos (63) e, respetivamente, 90, 103 e 56 medidas preventivas previstas.

O ponto 1.1 da alínea c) da Recomendação $n^{0} 1 / 2009$ do CPC refere que deve ser indicada a definição e identificação dos vários responsáveis envolvidos na gestão do PGRCIC, sob a direção do órgão dirigente máximo. A maioria dos Institutos estudados identificava nos Planos o seu organograma, mas apenas uma minoria evidenciava os intervenientes e as respetivas funções e responsabilidades. O IP de Santarém apresentava uma identificação clara sobre os responsáveis, as suas funções e as suas responsabilidades. Também o IP da Guarda identificava os responsáveis, o seu cargo e o serviço a que pertenciam. Os restantes Institutos estudados limitavam-se ao organograma e a uma identificação dos responsáveis menos clara tendo em conta o recomendado.

O ponto 1.1 da alínea d) da Recomendação ${ }^{0} 1 / 2009$ do CPC refere, ainda, que deve ser elaborado um relatório anual sobre a execução do Plano. Entre os Institutos em análise, apenas, o IP Leiria divulgava os relatórios relativos ao período considerado. Daí que, dada a escassez de informação, optou-se por não efetuar a análise destes documentos.

\subsection{Análise Quantitativa}

Efetuou-se, ainda, a análise das variáveis de natureza quantitativa (número de escolas e de cursos, população e massa monetária) com o objetivo de tentar perceber se o número de riscos/processos estaria dependente dessas variáveis, na expetativa de que pudessem influenciar positivamente o número de riscos/processos.

Em relação à influência da dimensão das organizações no nível de divulgação de informação sobre o risco Linsley e Shrives (2006) e Kajüter (2006) verificaram que as grandes empresas financeiras tendiam a apresentar um nível mais elevado de divulgação de informação sobre o risco (WOODS, 2008). Mais concretamente no setor público, GarcíaSánchez, Aceituno e Domínguez (2013) referem, também, essa relação entre a dimensão da organização e o nível de divulgação de informação sobre o risco no sentido em que a dimensão tem uma relação positiva com a divulgação de informação social e ambiental. De acordo com os autores, esta situação estava relacionada com o facto de quanto maior o município, maior o número de partes interessadas, o que incentivaria à divulgação sobre a sua sustentabilidade. Assim, no presente estudo utilizou-se, por analogia com os municípios, os IP's públicos para a criação das hipóteses a testar. Deste modo, foram criadas as seguintes hipóteses, considerando que o nível de divulgação de informação sobre o risco é medido pelo número de riscos:

○ H1: O número de escolas que constituem o IP está positivamente relacionado com o nível de divulgação de informação sobre o risco

○ H2: O número total de cursos conferentes de grau, existentes no IP está positivamente relacionado com o nível de divulgação de informação sobre o risco

○ H21: O número de mestrados existentes no IP está positivamente relacionado com o nível de divulgação de informação sobre o risco

○ H22: O número de licenciaturas existentes no IP está positivamente relacionado com o nível de divulgação de informação sobre o risco

○ H3: O total de população do IP está positivamente relacionado com o nível de divulgação de informação sobre o risco 
○ H31: O número de docentes do IP está positivamente relacionado com o nível de divulgação de informação sobre o risco

○ H32: O número de funcionários não docentes do IP está positivamente relacionado com o nível de divulgação de informação sobre o risco

○ H33: O número de estudantes do IP está positivamente relacionado com o nível de divulgação de informação sobre o risco

○ H4: O total de massa monetária transacionada em 2010 pelo IP está positivamente relacionado com o nível de divulgação de informação sobre o risco

No mesmo sentido e partindo do estudo de García-Sánchez, Aceituno e Domínguez (2013), criaram-se de forma idêntica as hipóteses considerando como variável dependente o número de processos:

○ H5: O número de escolas que constituem o IP está positivamente relacionado com o número de processos

○ H6: O número total de cursos conferentes de grau, existentes no IP está positivamente relacionado com o número de processos

○ H61: O número de mestrados existentes no IP está positivamente relacionado com o número de processos

○ H62: O número de licenciaturas existentes no IP está positivamente relacionado com o número de processos

○ H7: O total de população do IP está positivamente relacionado com o número de processos

○ H71: O número de docentes do IP está positivamente relacionado com o número de processos

○ H72: O número de funcionários não docentes do IP está positivamente relacionado com o número de processos

○ H73: O número de estudantes do IP está positivamente relacionado com o número de processos

○ H8: O total de massa monetária transacionada em 2010 pelo IP está positivamente relacionado com o número de processos

Inicialmente e, dado que as variáveis em análise são todas de natureza quantitativa, decidiu-se testar as hipóteses definidas anteriormente através da regressão linear simples e múltipla. Toda a análise estatística cujos resultados são descritos em seguida foi efetuada utilizando o software SPSS, versão 21.

Começou-se por validar o pressuposto da normalidade das variáveis presentes no modelo de regressão linear. Utilizaram-se dois testes de hipóteses, Kolmogorov-Smirnov e Shapiro-Wilk, tendo-se verificado que em $90 \%$ das situações a Normalidade foi assegurada para um nível de significância de 1\%. De seguida construiu-se a matriz de correlações entre todas as variáveis em análise. Utilizou-se o coeficiente de correlação de Pearson, tendo-se de imediato verificado que os valores deste coeficiente entre as variáveis dependentes (número de riscos e número de processos) e cada uma das variáveis independentes eram, na maioria dos casos, bastante baixo (próximo de zero). Esta primeira análise pressupunha uma fraca relação linear entre as possíveis variáveis independentes e cada uma das variáveis dependentes. 
Apesar das fracas expetativas decidiu-se construir os diversos modelos de regressão linear que permitiriam validar ou não cada uma das hipóteses supracitadas. Começou-se pelo modelo de regressão linear múltipla, considerando a variável dependente, número de riscos, em função das variáveis independentes (número de escolas e de cursos, total de população e da massa monetária transacionada). De seguida construíram-se os modelos de regressão linear simples considerando cada uma das variáveis independentes isoladamente. E finalmente, de forma individual, analisou-se a validação de cada uma das sub-hipóteses.

Em nenhum dos modelos foi possível validar as hipóteses subjacentes. Todos eles apresentaram um coeficiente de determinação muito baixo, na sua maioria de valores inferiores a 0,2 , indicando uma fraca qualidade de ajustamento do modelo aos dados. Nenhum modelo foi considerado estatisticamente significativo, para qualquer nível de significância. Estes resultados indiciam a inexistência de relação entre a dimensão do IP e o número de riscos e processos divulgados, o que não é consistente com Linsley e Shrives (2006 apud WOODS, 2008) e, mais especificamente para o setor público, também, não é consistente com Garcia-Sánchez, Aceituno e Domínguez (2013).

De seguida repetiu-se o procedimento considerando desta vez como variável dependente o números de processos. O número de processos está fortemente correlacionado com o número de riscos pelo que os resultados obtidos foram em tudo idênticos aos anteriores. Também neste caso nenhum dos modelos se mostrou estatisticamente significativo e a qualidade do ajustamento voltou a ser bastante fraca.

Uma vez que os resultados da aplicação dos modelos de regressão linear foram fracos e não permitiram a validação das hipóteses definidas decidiu-se utilizar uma nova abordagem. Visando a aplicação do modelo de regressão logística, definiu-se o índice/ratio entre o número de riscos de cada IP e o número total de riscos. Como variável dependente do modelo foi utilizado o logaritmo Neperiano do supracitado ratio. Nesta fase decidiu-se apenas trabalhar com as hipóteses principais $\mathrm{H} 1$ a $\mathrm{H} 4$ definidas anteriormente.

Tal como no caso anterior, em primeiro lugar foi definido um modelo de regressão logística múltipla mantendo-se as quatro variáveis independentes. De seguida construíram-se quatro modelos de regressão logística de forma a analisar individualmente a relação entre cada uma das variáveis independentes e a variável dependente.

Mais uma vez chegou-se à conclusão de que não existia evidência estatística de que as hipóteses H1, H2, H3 e H4 se verificassem. Ou seja, com base na amostra utilizada, não foi possível encontrar uma relação estatisticamente significativa entre qualquer uma das variáveis independentes e a divulgação de informação sobre o risco. De novo, também, estes resultados indicaram a inexistência de relação entre a dimensão do Instituto e o número de riscos e processos divulgados, o que não é consistente com Garcia-Sánchez, Aceituno e Domínguez (2013).

Quer no modelo de regressão múltipla quer nos modelos individuais o valor dos coeficientes obtidos foi aproximadamente zero, sendo que na maioria dos casos apresentava sinal negativo, não se conseguindo atestar a relação positiva entre as variáveis independentes e a divulgação de informação sobre o risco, como seria esperado. Os p-values fornecidos pela regressão logística eram, em geral, superiores a 0,05 , evidenciando a inexistência de significância estatística nas diversas hipóteses testadas.

Individualmente, ou de uma forma global, não foi possível demonstrar a existência de uma relação positiva entre as variáveis independentes consideradas e a divulgação de informação sobre o risco, quer através do número de riscos e do número de processos 
utilizando a regressão linear quer criando ratios e utilizando a regressão logística. Tais resultados poderão estar relacionados com a dimensão da amostra e a falta de variabilidade. $\mathrm{O}$ facto de não se ter encontrado qualquer relação positiva entre as variáveis independentes e a divulgação de informação sobre o risco, não significa que ela não exista.

\section{Conclusões}

A gestão do risco é uma atividade fundamental para qualquer organização, quer ela se insira no setor privado ou no setor público. O Tribunal de Contas parece defender esta posição ao emitir a Recomendação $n^{0} 1 / 2009$, sobretudo no que concerne aos riscos de corrupção e infrações conexas.

O presente estudo teve como objetivo realçar a importância da divulgação da informação sobre o risco e responder às questões de pesquisa identificadas. Desta forma e em relação à questão se os PGRCIC dos IP's públicos portugueses estavam em conformidade com a Recomendação $\mathrm{n}^{0} 1 / 2009$ de 1 de Julho do CPC, parece possível concluir que existiam, não só, níveis diferentes de divulgação de informação sobre o risco como existiam mesmo casos de ausência dessa divulgação.

No que concerne à divulgação da identificação e hierarquização dos riscos pelos IP's analisados, todos cumpriram o disposto no Despacho $n^{0} 36 / 2009$, mas no que respeita à hierarquização dos riscos somente cinco a faziam cumprindo com o mesmo Despacho e, também, por isso não se enquadravam na FERMA (2003). Ainda, nove IP's não divulgavam a forma como identificavam os riscos e, somente, dois referiam o modo de hierarquização. Estes factos evidenciam uma diferente convergência com o previsto na Recomendação $\mathrm{n}^{\mathrm{o}} 1 / 2009$.

Em relação às tipologias de risco presentes nos PGRCIC, verificou-se que tinham como referência a mesma tipologia utilizada pela FERMA (2003). Isto é, utilizavam os riscos estratégicos, financeiros, operacionais e perigos.

No que respeita à enumeração de processos, todos os IP's estudados os identificavam, o mesmo acontecendo com as medidas de prevenção a adotar, o que vai ao encontro da Recomendação n ${ }^{0} 1 / 2009$ do CPC.

Verificou-se, igualmente, um nível diferente de divulgação de informação relacionada com a definição e identificação dos responsáveis de gestão dos PGRCIC. Apesar de a maioria dos IP's apresentarem o seu organograma, poucos evidenciavam os intervenientes, as suas funções e responsabilidades. Enquanto dois Institutos referiam estes aspetos, os restantes onze limitavam-se ao organograma e a uma identificação menos clara dos responsáveis. Daqui poder-se-á concluir que não divulgavam esta informação em conformidade com a Recomendação $\mathrm{n}^{\mathrm{o}} 1 / 2009$ do CPC.

Para responder às questões se existiam e quais as variáveis que influenciavam a quantidade de riscos das Instituições e se existiam e quais as variáveis que influenciavam a quantidade de processos das instituições, foi efetuada a análise das variáveis de natureza quantitativa baseada na dimensão da organização e no nível de divulgação de informação sobre o risco tal como Garcia-Sanchez, Aceituno e Domínguez (2013), tendo sido definidas várias hipóteses (H1 a H8). Após tratamento estatístico pelo software SPSS versão 21, verificou-se em relação ao coeficiente de correlação de Pearson, entre as variáveis 
dependentes e variáveis independentes valores bastante baixos, próximos do zero. Apesar disso construiu-se modelos de regressão linear para validação ou não das hipóteses.

A partir dos vários modelos utilizados não foi possível validar as várias hipóteses. Estes factos indicavam as expetativas de correlações baixas nas hipóteses identificadas, e não permitiram a sua validação. Em função destes resultados criou-se uma nova abordagem utilizando o modelo de regressão logística em que se trabalhou somente com as hipóteses principais (H1 a H4). De novo se concluiu que não existia relação estatisticamente significativa entre as variáveis independentes e a divulgação de informação sobre o risco.

Estes resultados não são de modo a confirmar as expetativas que existiam baseadas no estudo de Garcia-Sanchez, Aceituno e Domínguez (2013) e que consistiam no impacto positivo que a dimensão da organização teria sobre o nível de divulgação de informação sobre o risco, isto é, quanto maior a dimensão maior o nível de divulgação associado a cada organização.

Este estudo enforma de algumas limitações, pois desde logo foca-se na análise, apenas, dos PGRCIC e de um único ano uma vez que era o único período de comparação entre os treze Institutos que divulgavam essa informação. Esta situação limitou a obtenção de resultados não permitindo uma análise evolutiva do problema e, daí, não permitindo também retirar qualquer tipo de conclusão estatisticamente significativa. Além de que, como referido, não foi possível analisar, por falta de documentos, os relatórios de execução dos PGRCIC e os relatórios de gestão e contas.

Quanto às linhas de investigação futuras possíveis e tendo em conta as limitações enunciadas, considera-se interessante um estudo evolutivo em relação à execução dos PGRCIC, nas suas implicações para elevar o nível e a qualidade da divulgação de informação sobre o risco. Também se considera interessante efetuar, no futuro, uma comparação entre os acontecimentos ligados à corrupção e infrações conexas antes e depois da implementação dos PGRCIC. Até porque, como referem Cunha, Serra e Costa (2012, p.703), "até ao momento, não existem estudos empíricos que comprovem a eficácia desta medida de prevenção da corrupção". Também, seria interessante a triangulação de fontes, como se pretendia, recorrendo aos relatórios de execução dos PGRCIC e aos relatórios de gestão e contas dos IP's logo que sejam disponibilizados.

\section{Referências}

ALMEIDA, J. R.. Contabilidade de Custos para as Autarquias Locais. Modelo para o Sector Público Administrativo. Porto: Vida Económica. 2005.

ALVES, M. T.. A Importância de Divulgação da Informação sobre o Risco do Negócio. 2005. 5xx f. Tese de Doutoramento. Doutoramento em Gestão, especialidade Contabilidade do ISCTE. Lisboa. 2005.

ARAÚJO, J. P.. A Implementação do Plano Oficial de Contabilidade Pública e dos Planos Sectoriais dos Serviços Autónomos da Administração Central: Estudo e Análise. 2005. Dissertação de Mestrado em Contabilidade e Auditoria. Disponível em: http://repositorium.sdum.uminho.pt. Acesso em: 25 jul. 2012. 
ASSEMBLEIA DA REPUBLICA. Resolução da Assembleia da Republica nº 47/2007.

Association of Certified Fraud Examiners (ACFE). Report to the Nations on Occupational Fraud and Abuse. Global Fraud Study. 2012.

ÁVILA, M. G.. Gestão de Riscos no Sector Público: Controle estratégico para um processo decisório eficiente. 2013. Disponível em: http://semanaacademica.org.br. Acesso em: 20 jul. 2013.

BEATTIE, V.; MCINNES, B.; FEARNLEY, S.. A Methodology for Analysing and Evaluating Narratives in Annual Reports: A Comprehensive Descriptive Profile and Metrics for Disclosure Quality Attributes. University of Glasgow. Accounting Forum. 2004.

BEJA, R.. Risk Management, Gestão, Relato e Auditoria. Lisboa: Áreas Editora. 2004.

CHARTERED INSTITUTE OF MANAGEMENT ACCOUNTANTS (CIMA). Fraud risk management: A guide to good practice. 2008. Disponível em: http://www.cimaglobal.com. Acesso em: 22 jun. 2014.

COMMITTEE OF SPONSORING ORGANIZATIONS OF THE TREADWAY COMMISSION (COSO). Enterprise Risk Management - Integrated Framework Executive Summary. september 2004. Disponível em: http://www.coso.org. Acesso em: 22 jun. 2014.

COMMITTEE OF SPONSORING ORGANIZATIONS (COSO). COSO. 2012. Disponível em: http://www.coso.org. Acesso em: 12 ago. 2013.

CONSELHO COORDENADOR DOS INSTITUTOS SUPERIORES POLITÉCNICOS

(CCISP). Anuário Financeiro das Instituições Públicas de Ensino Superior Politécnico. 2010. Disponível em: http://www.ccisp.pt. Acesso em: 21 jun. 2014.

CONSELHO DE PREVENÇÃO DA CORRUPÇÃO (CPC). Recomendação nº1/2009 sobre Planos de Gestão de Riscos de Corrupção e Infracções Conexas. Diário da República - 2ª série - no 140. 22 jul. 2009.

CONSELHO DE PREVENÇÃO DA CORRUPÇÃO (CPC). Relatório de Actividades 2012. Lisboa. 2013.

CONSTITUIÇÃO DA REPÚBLICA PORTUGUESA. VII Revisão Constitucional. 2005. Disponível em: http://www.parlamento.pt. Acesso em: 27 jun 2014.

COOPER, D.. Specialists in Strategic, Enterprice and Project Risk Management. Tutorial Notes: The Australian and New Zealand Standard ou Risk Management AS/NZS 4360:2004. Austrália: Broadleaf Capital Internacional PTY LTD. 2007. 
CUNHA, R. A. S.; SERRA, S. A. E.; COSTA, M. M. O.. Medidas de combate à corrupção em Portugal. In: Tourism and Management Studies International conference Algarve 2012. V. 2, p. 693-705.

FEDERATION OF EUROPEAN RISK MANAGEMENT ASSOCIATIONS (FERMA). Norma de Gestão de Riscos. Bélgica: The Institute of Risk Management (IRM), The Association of Insurance and Risk Managers (AIRMIC) e ALARM The National Forum for Risk Management in the Public Sector. 2003.

GARCÍA-SÁNCHEZ, I.; ACEITUNO, J.; DOMÍNGUEZ, L.. Determinants of corporate social disclosure in Spanish local governments. Journal of Cleaner Production, v.39, p. 60-72, jan. 2013.

HILL, S. Texto III, Guia sobre a gestão de riscos no serviço público. Canada School of Public Service, 37-49. Brasilia: Escola Nacional de Administração Pública. 2006.

INSTITUTO BRASILEIRO DE GOVERNANÇA CORPORATIVA (IBGC). Guia de Orientação para Gerenciamento de Riscos Corporativos. 2007. Disponível em: http://www.ibgc.org.br. Acesso em: 31 set. 2014.

INSTITUTO POLITÉCNICO CASTELO BRANCO. PGRCIC 2009/2010. Castelo Branco. 2009.

INSTITUTO POLITÉCNICO CÁVADO E DO AVE. PGRCIC 2009/2010. Cávado e do Ave. 2009.

INSTITUTO POLITÉCNICO COIMBRA. PGRCIC 2009/2010. Coimbra. 2009.

INSTITUTO POLITÉCNICO DE BEJA. PGRCIC 2009/2010. Beja. 2009.

INSTITUTO POLITÉCNICO GUARDA. PGRCIC 2009/2010. Guarda. 2009.

INSTITUTO POLITÉCNICO LEIRIA. PGRCIC 2009/2010. Leiria. 2009.

INSTITUTO POLITÉCNICO LISBOA. PGRCIC 2009/2010. Lisboa. 2009.

INSTITUTO POLITÉCNICO PORTALEGRE. PGRCIC 2009/2010. Portalegre. 2009.

INSTITUTO POLITÉCNICO PORTO. PGRCIC 2009/2010. Porto. 2009.

INSTITUTO POLITÉCNICO SANTARÉM. PGRCIC 2009/2010. Santarém. 2009.

INSTITUTO POLITÉCNICO SETÚBAL. PGRCIC 2009/2010. Setúbal. 2009.

INSTITUTO POLITÉCNICO TOMAR. PGRCIC 2009/2010. Tomar. 2009. 
INSTITUTO POLITÉCNICO VIANA DO CASTELO. PGRCIC 2009/2010. Viana do Castelo. 2009.

INSTITUTO POLITÉCNICO VISEU. PGRCIC 2009/2010. Viseu. 2009.

INTERNATIONAL FEDERATION OF ACCOUNTANTS COMMITTEE (IFAC). 2012. Disponível em: http://www.ifac.org/about-ifac/organization-overview. Acesso em: 9 jul. 2012.

INTERNATIONAL FEDERATION OF ACCOUNTANTS COMMITTEE (IFAC). (2012 a). Disponível em. http://www.ifac.org/public-sector/about-ipsasb. Acesso em: 9 jul. 2012.

INTERNATIONAL FEDERATION OF ACCOUNTANTS COMMITTEE (IFAC). (2012 b). Disponível em: http://www.ifac.org/sites/default/files/publications/files/PPP\%205\%20(2).pdf. Acesso em: 9 jul. 2012.

INTERNATIONAL FEDERATION OF ACCOUNTANTS (IFAC). Normas Internacionais de Contabilidade para o Setor Público (IPSAS). Conselho Federal de Contabilidade. 2010.

INTERNATIONAL ORGANIZATION FOR STANDARDIZATION (ISO). IEC GUIDE 73. Risk management - Vocabulary. Genebra: ISO Technical Management Board Working Group. 2009.

INTERNATIONAL ORGANIZATION FOR STANDARDIZATION (ISO). ISO. 2012. Disponível em: http://www.iso.org/iso. Acesso em: 5 set. 2012.

KAJÜTER, P.. Risikoberichterstattung: empirische befunde und der entwurf des DRS5. n. 3, p. $105-111.2001$

LINSLEY, P.; SHRIVES, P.. Risk Management and Reporting Risk in the UK. Journal of Risk, v.3, p. 115-129. 2000.

LINSLEY, P.; Shrives, P.. Transparency and the disclosure of risk information in the banking sector. Journal of Financial Regulation and Compliance, v. 13, p. 205-214. 2005.

MACIEIRA, A. Gestão Baseada em Riscos: Reinventando o Papel da Gestão de Riscos Integrada ao Negócio. (Elogroup). 2008. Disponível em: http://www.elogroup.com.br. Acesso em: 23 out. 2013.

MOREAU, F.. Compreender e gerir os riscos. Lisboa: Bertrand Editora. 2003.

NOGUEIRA, S.; CARVALHO, J.. O sistema de informação contabilística da Administração Públlica portuguesa segundo a perspectiva de "especialistas": estudo empírico. Associação de Docentes de Contabilidade do Ensino Superior. 2007. Disponível em:

https://bibliotecadigital.ipb.pt. Acesso em: 14 dez. 2012. 
PENHA, J. C.; PARISI, C.. Um caminho para integrar a gestão de riscos à controladoria. 2005. Disponível em: http://www.intercostos.org. Acesso em: 24 set. 2012.

SHENKIR, W.; WALKER, P. Enterprise risk management: Tools and techniques for effective implementation. Institute of Management Accountants. 2007. Disponível em:

http://poole.ncsu.edu. Acesso em: 26 mai 2014.

SILVA, J. H.. Gestão do Risco - Parte I: gestão do risco, biologia da empresa e liderança. 2009. Disponível em: http://jorgesilva.pbworks.com. Acesso em: 20 set. 2013.

SOARES, M.; SCARPIN, J. A convergência da contabilidade pública nacional às normas internacionais e os impactos da aplicação da DRE na administração pública. Revista Catarinense, v.9, p.25-42, ago./nov. 2010.

TEIXEIRA, A. B.. A Contabilidade como Sistema de Informação nas Instituições do Ensino Superior Público em Portugal - O caso da Escola Superior de Ciências Empresariais. Tese de Doutoramento em Gestão, Universidade Aberta, Lisboa. 2009.

TEIXEIRA, M. D.. O Contributo para a Auditoria Interna para uma Gestão Eficaz. Dissertação de Mestrado em Contabilidade e Auditoria. 2006. Disponível em: https://repositorioaberto.uab.pt. Acesso em: 25 out. 2012.

TRANSPARÊNCIA E INTEGRIDADE, Associação Cívica (TIAC). Sistema Nacional de Integridade (SNI). Lisboa. 2012.

TRANSPARENCY INTERNACIONAL (TI). Corruption Perceptions Index 2009. Germany. 2009.

TRIBUNAL DE CONTAS. Despacho nº 36/2009 - GP, de 30 de Outubro. 2009.

URBANO, C.. O Ensino Politécnico - (re)definição e (re)posicionamento no panorama da formação superior em Portugal. IV Congresso Português de Sociologia. Lisboa. 2008.

WOODS, M.. International Risk Management. 1 ed.. Oxford: CIMA Publishing. 2008. 